\title{
Areas Of Cross-Cultural Difference In The Workplace
}

Mario E. Castaneda, California State University at Los Angeles, USA Justin Bateh, Florida State College at Jacksonville, USA Wilton Heyliger, Walden University, USA

\begin{abstract}
In the last 30 years, there has been a shift towards using multicultural management strategies. The constant shifts taking place in multi-ethnic, multicultural, and multinational workforces indicate that both administrators of these organizations and higher education practices must evolve to adapt to needs for changing skill sets. A multicultural workforce offers advantages in that businesses may reach out effectively to various stakeholders. Leaders do well to cultivate an organizational culture that incorporates flexibility, understanding, and acceptance of alternate values, especially when working in foreign locations or multi-national organizations. Understanding of differences in cultural values and customs may reduce conflict and increase collaboration. To meet these challenges, leaders must be trained and educated to develop flexibility, understanding, and acceptance of alternate values when working in foreign locations or multi-national organizations. This article points out important areas of difference for organizations to address.
\end{abstract}

Keywords: Multicultural Management; Organizational Culture; Cross Cultural Paradigm

\section{INTRODUCTION}

ncreasingly, organizations find that their work associates, customers, and clients include persons of other ethnicities and nationalities. As a result, a workforce comprised of persons from different backgrounds can help an organization effectively reach out to a diverse customer base and clientele (Kelly, 2009). To meet current challenges, organizations must have effective communication and collaboration among the various segments to ensure that everyone has an adequate understanding and acceptance of the cultural beliefs of their coworkers (Castaneda \& Bateh, 2013). Yet, creating an organizational culture in which differences in cultural values and customs are respected and understood poses a challenge. This article covers some of the most important divisions in perspective. A workplace has options to choose from and creates balance when the culture includes valuing of alternate perspectives and preferences. These options offer an advantage of flexibility and adaptability when addressing stakeholders whose cultural backgrounds are understood.

\section{STATEMENT OF THE PROBLEM}

A major challenge for multicultural management is the different cultural beliefs, practices, and traditions that are embraced by various segments of employees (Edewor, 2010). A lack of understanding and valuing of cultural differences can create animosity and division between employees, leading to internal challenges that will hinder overall performance (Devine, 2007). The groups in the minority, whose cultural values are not as well represented, may believe that select segments are trying to impose their belief system upon them. When this happens, misunderstandings and resentment often follow (Edewor, 2010). Those within that minority may feel a profound disconnect with the organizational leadership and its goals. 


\section{AREAS OF CROSS-CULTURAL DIFFERENCE}

This intent of this article is to raise awareness of possible differences, not to describe specific cultures as having one or another preference. The Communicaid (n.d.) files are a valuable resource for information on specific cultural values and customs for various national and cultural groups.

\section{Power structure}

Power structure is one significant part of organizational culture. Power structure relates to two separate polarities. In a hierarchical structure, decision-making is solely the prerogative of the managerial staff, even if there is consultation with subordinates. This structure is also referred to as vertical. In an egalitarian arrangement, managers share decision-making, to some degree, with subordinates. This structure is also referred to as flat or horizontal.

Power structure also relates to another polarity. Individualism focuses on the well-being of the individual over the group (Gullestrap, 2009), whereas collectivism regards the group as more important than the individual. Collectivism is commonly embraced by Eastern cultures as well as the Middle East (Foss, 2008; Gullestrap, 2009), while individualism, at its most pronounced, characterizes the United States. Individualizm emphasizes competition as promoting individual and, ultimately, collective well-being, whereas collectivism emphasizes loyalty and group solidarity as promoting the interest of all and, ultimately, the individual.

In vertical individualist societies or cultural contexts, such as the United States, Great Britain, and France, people tend to be concerned with improving their individual status and distinguishing themselves from others via competition, achievement, and power (Nelson, 2012; Shavitt, Torelli, \& Riemer, 2010). In contrast, in horizontal individualist societies or cultural contexts, such as Sweden, Denmark, Norway, and Australia, people prefer to view themselves as equal to others in status, and eschew status differentiation (as cited in Shavitt et al., 2010), though still emphasizing the individual's responsibility for self. Vertical collectivism is when persons look at themselves as a part of a larger group (Gullestrap, 2009). They will accept both the strengths and weaknesses of everyone in order to help make them collectively become stronger, but status is important, as in the Middle East, East Asia, and Native American cultures (Foss, 2008). Horizontal collectivism is when the individual has a certain amount of freedom away from the group and in the event that some kind of inequality is uncovered, they will accept it (Gullestrap, 2009).

In the past, management strategies in the United States often focused on vertical individualism, emphasizing hierarchy rather than valuing equality. These are prominent cultural features that have long been a focus of discussion and disagreement in multi-cultural settings.

As an example of valuing both cultural aspects, the theory and practice of total quality management (TQM) originally developed in the United States, yet it was refined in Japan according to collectivist principles. Many managers in the United States recognized the value and effectiveness of combining principles of individualism and collectivism, and thus adopted the Japanese version of TQM (Brennan, 2007). Japanese TQM emphasizes the idea that everyone plays an important part in helping the company to be successful. If there is a problem with quality, each person has the power to address the problem before it becomes larger (Brennan, 2007). During this process, no one is seen as superior to the others. Instead, everyone collectively works to achieve the objectives of the organization (Brennan, 2007).

\section{Gender differences}

More pronounced gender differences are found in Eastern, Middle Eastern, as well as in Latino cultures. In these cultures, traditional homemaker roles are more revered for women. In contrast, in cultures in which women make up a large percentage of the workforce and are more economically on par with men, women receive and expect similar treatment to their male co-workers, such as in the United States, Northern Europe, and India's college-educated class. Still, there may be some cultural restrictions, especially regarding how friendly a man may or may not behave toward a woman in a business setting and, generally, in public. 


\section{Formality}

Formality differs across occupations as well as locations, but there are some generalities that apply to cultural groups. In informal cultures, the business environment appears more friendly, such as in Latin America, Middle East, and Africa, and establishing personal contacts is essential for business dealings. Physical familiarity commonly seen in these cultures includes handshaking, close personal space, and hugging or backslapping (Gorril, 2007). Conversation in the workplace need not be confined to business topics.

In formal cultures, such as in the Middle East, East Asia, the United States, and Europe, these titles are used and respected. The work environment requires more conservative clothing. In the Middle East, business attire for women is modest and conservative and status consciousness demands use of titles as well as show of respect from subordinates (Foss, 2008). Although more formal, establishing personal contacts and trust is essential for business dealings in the Middle East and East Asia.

\section{Time}

Generally, in less formal cultures, avoid forcing deadlines or rushing deals. In cultures such as those in Africa, the Middle East, the Pacific Islands, and Latin America (including Brazil), the approach to time is particularly casual and discussions may be lengthy. Deadlines are seen as goals, not mandates. Attempts to insist on firm commitments for meeting scheduling may prove counterproductive since the pace of business is slower and a protracted manner dominates. On the other hand, punctuality and timely decision-making is highly valued in Northern Europe, the United States, and Japan. To some extent, urban areas in any nation tend to be more deadlineoriented and time conscious in general when compared to their own rural areas, which tend to be more relaxed.

\section{Communication style}

A period of silence during a conversation may be a time of thought and reflection in some cultures, such as in East Asia and Native American cultures. In other cultures, it may be a sign that the situation has become uncomfortable or problematic or that the status of interactants is uncertain (Gorril, 2007; Neuliep, 2011). Some cultures have a more reserved and cautious manner of communication that aims to avoid conflict, such as in East Asia. An in-depth understanding of the culture is needed to interpret subtle cues. In the Middle East, communication is somewhat indirect and relies heavily on nonverbal cues and figurative speech, where information is not explicitly stated. For example, directly refusing a proposal is impolite (Foss, 2008). Japan, China, and some Native American cultures value concise and exact speech and do not value small talk (Neuliep, 2011). In comparison, those of a Western cultural background are frequently described as having an explicit approach to communication, for which the goal is to be direct and honest and often personal. In many cultures, a raised voice or interruption would be perceived as an insult, though such is expected in more direct cultures. Asians highly value humility and respect, thus they avoid direct public criticism of others (Neuliep, 2011). In Asian and Latino cultures, eye-contact is somewhat less frequent and steady persistent eye contact may be perceived as disrespect. In Western cultures, steady eye contact generally signifies trust.

\section{Ethics}

Particularly in the business setting, one should be aware whether visiting guests typically bring gifts and of what kind. In some Asian cultures, small gifts are tokens of respect (Gorrill, 2007), while in the United States, any gift might be seen as an attempt at ingratiation or bribery. In the Middle East, it is important to accept hospitality and gifts. It is acceptable to use personal relationships to further business interests. Rules and regulations can be bent if one has the right contacts (Foss, 2008). In some cultures, favoritism based on personal relationships has been the norm, such as in Latin America. Within work settings whose national or corporate cultures regard such as cronyism, it may be necessary to emphasize examples of how the organization and its stakeholders, including employees, prosper less when they accept practices that prevent the organization from employing the most qualified applicant for a position. An organization should find a way to respectfully honor in some fashion-other than promotionthose persons perceived as deserving acknowledgement. 


\section{CONCLUSION}

The constant shifts taking place in multi-ethnic workforces indicate that administrators must enable the workforce to reach out to various stakeholders by creating a work environment that embraces various attributes of the culture groups comprising a workforce (Buhalis, 2008; Hase, 2007). Such traditions promote effective relations with diverse clients and customers. Learning about cultural differences can foster mutual understanding that improves the work environment. Addressing cultural diversity in the workplace by groups, nationalities, or global regions is not a simple process. Though large cultural groups share many attributes, every nationality has specific differences. To succeed in this environment, administrators not only need to know the various cultural elements of their organization and locations, but also must be open to assess the particular cultural mix of each workplace. This leads to a more flexible organization that can adapt to a host of issues (Devine, 2007). When this happens, a common set of attributes will more likely be embraced by the employees whose different cultural beliefs are respected and incorporated into the organization's culture (Devine, 2007). These attributes are important for educators to convey to students to prepare new business leaders and personnel for multi-ethnic environments and to promote the emergence of new strategies for cultural integration.

\section{AUTHOR INFORMATION}

Mario E. Castaneda is an educational practitioner who has been a teacher, counselor, coordinator, and curriculum and staff development specialist. He has a doctoral degree in Education and Organizational Leadership from Pepperdine University and is currently a Professor of Education at California State University in Los Angeles. He has an MA in International and Multicultural Education from the University of San Francisco. He has taught both pre- and post-service teachers at various universities and colleges throughout California and Colorado. Dr. Castaneda's areas of interest include social sciences, second language acquisition, sheltered English for the secondary classroom, and cross-cultural and multicultural education. Dr. Castaneda's research has explored the social and educational success of the Central American community, the African legacy of Central America, issues of inter-group relations between ethnic minority groups, and museum community outreach programs for the Latino Community.

Justin Bateh is a business educator and practitioner who has been a faculty member at higher education institutions and a multidisciplinary consultant to small to mid-sized companies. He has an MBA from Nova Southeastern University and is a Doctor of Business Administration candidate at Walden University. He has developed professional and continuing education courses for state board licensed professionals, and taught both undergraduate and graduate courses in higher education institutions. Currently, he is an Assistant Professor of Business at Florida State College at Jacksonville. Mr. Bateh's areas of interest include operations management, organization development, leadership, job satisfaction, quantitative managerial decision making, multicultural management, and technology innovation. E-mail: jbateh@fscj.edu (Corresponding author)

Wilton Heyliger has a Ph.D. and MA from Indiana University, an MBA from Southern Illinois University at Edwardsville, and a BSME from Howard University. Currently, he is on the faculty at Walden University. He has been a member of the finance faculty of Howard University, teaching corporate and international finance. He later served on the finance faculties of the College of William and Mary and East Tennessee State University, Norfolk State University where he also served as Head of the Department of Finance and Marketing. He chaired the Department of Business Administration at Morris Brown College in Atlanta and was a visiting scholar at the Federal Reserve Bank of Atlanta. Dr. Heyliger also held several administrative positions in higher education. He served as Director of Special Projects and Economic Development in the Office of the President at Morris Brown College as well as chair and Professor of Economics at Atlanta Metropolitan College. Dr. Heyliger's scholarly research in banking was published in the Review of Black Political Economy, the Review of Business and Economics, and the Journal of Small Business Finance. Dr. Heyliger's current areas of specialization include international finance, economic development, and strategic management. His research interests include commercial banking, international trade, and commercial policy. 


\section{REFERENCES}

1. Brennan, R. (2007). TQM marketing perspectives. Quality Assurance in Education, 15(1), 44-60.

2. Buhalis, D. (2008). Progress in information technology and tourism management: 20 years on and 10 years after the Internet? Tourism Management, 29(4), 609-623. doi:10.1016/j.tourman.2008.01.005

3. Castaneda, M. E., \& Bateh, J. (2013). Strategies for multicultural management: communication and a common set of values. Journal of International Education Research, 9(1).

4. Communicaid. (n.d.). Business etiquette http://www.communicaid.com/

5. Devine, F. (2007). Managing cultural diversity. International Journal of Contemporary Hospitality Management, 19(2), 120-132.

6. Edewor, P. (2010). Diversity management, challenges and opportunities. International Journal of Diversity, 6(6), 89-195.

7. Foss, A. (2008). Doing business in the Middle East. Retrieved from http://www.communicaid.com

8. Gorrill, J. R. (2007). Intercultural communication. Retrieved from http://www.communicaid.com/

9. Gullestrap, H. (2009). The complexity of intercultural communication. Journal of Intercultural Communication, 6, 3-21.

10. Hase, S. (2007). Knowledge management. Journal of Knowledge Management, 11(1), 143-151.

11. Kelly, P. (2009). Group work and multicultural management education. Journal of Teaching in International Business, 20(1), 80-102. doi:10.1080/08975930802671273

12. Nelson, J. (2012). Developing efficacy beliefs for ethics and diversity management. Academy of Management Learning \& Education, 11(1), 49-68. doi:10.5465/amle.2009.0115

13. Neuliep, J. W. (2011). Intercultural communication: A contextual approach (5th ed.). Thousand Oaks, CA: Sage.

14. Shavitt, S., Torelli, C. J., \& Riemer, H. (2010). Horizontal and vertical individualism and collectivism: Implications for understanding psychological processes. In M. Gelfand, C-Y. Chiu, \& Y-Y. Hong (Eds.), Advances in culture and psychology (pp. 309-350). New York, NY: Oxford University Press. 
NOTES 